\title{
Pendampingan Berkelanjutan terhadap Pengembangan Pariwisata Desa Selopamioro
}

\author{
Yulita Kusuma Sari \\ Departemen Antarbudaya, Fakultas Ilmu Budaya, Universitas Gadjah Mada \\ Posel: yulita.kusumasari@ugm.ac.id
}

Tim Pengabdian Masyarakat:

Tular Sudarmadi, Popi Irawan, Marsono, Himpunan Mahasiswa Pariwisata (HIMAPA)

\begin{abstract}
Tourism development in rural areas with the method of community participation is an ideal condition that can be achieved on the basis of community spirit as basic and primary capital, supported by the availability of natural and cultural resources, good governance and supported by academics or other institutions as facilitators. In terms of developing tourism in Selopamioro Village, the study program of Tourism, Faculty of Cultural Sciences, Universitas Gadjah Mada acts as a supporting actor, through sustainable community service activities. Sustainability is important in developing tourism villages, it is intended that there is integration between activities carried out from year to year. Continuous mentoring are carried out from November 2016 until the end of 2018. There are significant developments from the existence of tourist attractions, especially natural tourism, and tourist accommodation in the form of homestays. Using the potential of institutional networks, the study program of Tourism collaborate with students, alumni, and hoteliers to jointly transfer knowledge to the community as owners and managers of tourist destinations. Interaction with the community through direct discussions in joint forums, or representatives from the arts community, PKK associations, youth associations, and tourism conscious groups. The results of the activity show that the assistance in developing sustainable tourism is able to build the spirit of the community to continue to participate in village tourism development. The spirit is the next capital of hard work, by utilizing institutional networks, the strength of the younger generation, village government support, and social media, the community has succeeded in generating new tourist attractions, improving accommodation facilities, and better tourism management.
\end{abstract}

Keywords: Community Service, tourism village, community participation, potential mapping, homestay

\footnotetext{
Abstrak

Pengembangan pariwisata di perdesaan dengan metode partisipasi masyarakat merupakan sebuah kondisi ideal yang dapat tercapai atas dasar semangat masyarakat sebagai modal dasar dan utama, didukung oleh tersedianya sumber daya alam dan budaya, pemerintahan yang baik, dan didukung oleh akademisi atau lembaga lain sebagai fasilitator. Dalam hal pengembangan pariwisata di Desa Selopamioro, Prodi Pariwisata FIB UGM berperan sebagai aktor pendukung melalui kegiatan pengabdian masyarakat yang berkelanjutan. Berkelanjutan penting dalam pengembangan desa wisata. Hal tersebut dimaksudkan agar ada integrasi antarkegiatan yang dilaksanakan dari tahun ke tahun. Kegiatan pendampingan berkelanjutan dilaksanakan mulai November 2016 hingga akhir 2018. Tercatat perkembangan yang signifikan dari keberadaan daya tarik wisata, khususnya wisata alam, dan akomodasi wisata berupa homestay. Menggunakan potensi jejaring kelembagaan, Prodi Pariwisata menggandeng mahasiswa, alumni, dan pihak perhotelan untuk
} 
bersama-sama melakukan transfer pengetahuan kepada masyarakat sebagai pemilik sekaligus pengelola destinasi wisata. Interaksi dilakukan bersama masyarakat melalui diskusi langsung dalam forum bersama, yakni bersama perwakilan dari komunitas seni, perkumpulan PKK, perkumpulan pemuda, dan kelompok sadar wisata (pokdarwis). Hasil kegiatan menunjukkan bahwa pendampingan pengembangan pariwisata secara berkelanjutan mampu membangun semangat masyarakat untuk terus berpartisipasi dalam kegiatan pengembangan pariwisata desa. Semangat tersebut yang menjadi modal kerja keras selanjutnya, dengan memanfaatkan jejaring kelembagaan, kekuatan generasi muda, dukungan pemerintah desa, dan media sosial, masyarakat berhasil memunculkan atraksi wisata baru, memperbaiki fasilitas akomodasi, serta manajemen pariwisata yang lebih baik.

Kata Kunci: Pengabdian kepada Masyarakat, desa wisata, partisipasi masyarakat, pemetaan potensi, homestay

\section{Pendahuluan}

Industri pariwisata dalam beberapa dekade terakhir telah dipercaya dalam mengurangi kemiskinan serta meningkatkan pendapatan daerah dan nasional (Gross Domestic Product) $G D P)$. Sebagai contoh, pariwisata sebagai penggerak ekonomi, memberi manfaat secara langsung pada tingkat ketersediaan dan keterserapan tenaga kerja. Sebagai contoh, di Asia Pasifik, seperti dikutip dalam laporan tahunan WTTC (World Travel and Tourism Council) tahun 2016, kontribusi sektor perjalanan dan pariwisata terhadap pertumbuhan GDP di Indonesia adalah 5,8\%.

... the strongest growth was experienced in Southeast Asia (8.3\%), which has benefited with rapid growth in the China outbound market, and South Asia (7.9\%), with Sri Lanka (10.7\%), Thailand (10.7\%), Vietnam (10.7\%), Philippines (8.9\%), Singapore (8.7\%), India (8.5\%), and Indonesia (5.8\%) contributing impressively. (Travel \& Tourism Global Economic Impact \& Issues 2017, WTTC, 2016).

Di dalam laporan yang sama disebutkan bahwa industri perjalanan dan pariwisata ini juga diprediksikan memberi dampak langsung yang tinggi terhadap keterserapan tenaga kerja pada rentang waktu 2017-2027, Indonesia menduduki peringkat ke-9 dari 10 negara di dunia dengan prediksi 25.169.000 lapangan pekerjaan terkait industri ini.

Selain imbas ekonomi, beberapa studi menyebutkan bahwa pariwisata dapat digunakan sebagai alat untuk meningkatkan nilai dan kerukunan sosial, meningkatkan sinergi kerja sama antarlembaga daerah, dan memberi kontribusi pada pelestarian warisan budaya serta lingkungan hidup. Dengan prediksi benefit yang besar, maka tak mengherankan bahwa industri ini kemudian menjadi anak emas, yakni sebagai sektor andalan pembangunan daerah. Tiap daerah berlomba-lomba dalam pengembangan pariwisata, memanfaatkan sebaik mungkin dan semaksimal mungkin potensi daerah, baik sumber daya alam maupun budaya untuk dikembangkan sebagai daya tarik wisata. Salah satu kebijakan metode pengembangan pariwisata di Indonesia adalah dengan pengembangan produk baru berupa daya tarik wisata, yang dapat diartikan sebagai usaha untuk memperbaiki produk yang sedang berjalan atau menambah jenis produk yang dihasikan ataupun yang akan dipasarkan (Yoeti, 2007:96). Pengembangan produk pariwisata sangat bergantung pada ketersediaan sumber daya di tiap-tiap daerah. Hal inilah yang menjadi tantangan tersendiri bagi pengembangan pariwisata di Indonesia. 
Ditinjau dari keadaan alam dan geografisnya, posisi strategis di garis khatulistiwa dan berklim tropis menjadikan Indonesia memiliki kekayaan alam yang berlimpah. Selain itu, kekayaan budaya merupakan hasil pengetahuan sistem hidup masyarakat lokal yang dipengaruhi oleh iklim, lingkungan, dan sejarah yang dikumpulkan sejak lama (collective memory).

Perda No. 1 Tahun 2012 tentang Rencana Induk Pengembangan Pariwisata Daerah (RIPPARDA) Daerah Istimewa Yogyakarta membagi wilayah DIY menjadi 12 kawasan strategis pengembangan pariwisata (KSPP), dengan daerah Bantul yang menjadi daerah strategis pariwisata berbasis alam. Pembagian kawasan strategis ini telah dipertimbangkan dan diputuskan sesuai dengan keberadaan potensi masing-masing kawasan. Sebagai salah satu bentuk pengembangan pariwisata berbasis alam, tentunya desa wisata atau wisata berbasis pedesaan merupakan pilihan tepat bagi desa-desa yang masuk dalam kawasan ini.

Menurut Damanik (2014:3), desa wisata merupakan sebuah istilah yang jarang ditemukan dalam literatur. Lebih lanjut disebutkan bahwa Desa Wisata dapat diartikan sebagai desa yang dengan sengaja dibangun — yang secara alami memiliki kemampuanuntuk menarik kunjungan wisatawan karena ketersediaan potensi atraksi alam dan budayanya. Kemampuan alami desa memanfaatkan potensi alam dan budaya tidak lepas dari kemampuan masyarakat desa untuk berperan sebagai pelaku kegiatan wisata. Selain itu, desa wisata hendaklah memberi manfaat yang sebesar-besarnya bagi masyarakat desa tersebut. Oleh karena itu, kegiatan wisata merupakan kegiatan yang inisiatifnya berasal dari masyarakat, dilaksanakan bersama oleh masyarakat, dan dimanfaatkan pula hasilnya oleh masyarakat. Hal tersebut sesuai dengan semangat pengembangan desa dengan metode partisipasi masyarakat (community participatory), yang pengembangan masyarakatnya, mulai dari tahap perencanaan hingga tahap pelaksanaan dan evaluasi, didominasi oleh peran masyarakat.

Desa Selopamioro, Kecamatan Imogiri menjadi salah satu desa yang masuk dalam kawasan pengembangan pariwisata alam yang memiliki kekayaan alam dan budaya. Pada 2014, Desa Selopamioro merupakan salah satu desa yang dicanangkan sebagai desa budaya oleh pemerintah DIY karena memiliki keragaman seni dan kelompok kesenian. Menurut kepala desa Selopamioro, terdapat 80 kelompok kesenian yang berasal dari berbagai rentang usia. Kesenian yang ada, antara lain, jathilan, gejog lesung, gamelan, seni tari, kethoprak, karawitan, dalang anak, batik, kuliner (gethuk alot), dan dolanan bocah. Desa ini masuk dalam kategori desa budaya berkembang. Artinya, desa ini telah memiliki aktivitas dan kelompok-kelompok seni yang secara aktif berperan dalam menjaga dan melestarikan budaya tersebut. Kekayaan budaya inilah yang menjadi ide bagi masyarakat untuk menggunakannya sebagai daya tarik untuk mengembangkan kegiatan pariwisata. Selain kekayaan budaya, Desa Selopamioro memiliki beberapa titik daya tarik wisata yang telah dikenal oleh masyarakat, seperti Embung Song Bolong, Jembatan Gantung, dan Jembatan Edukasi Siluk.

Sebagai aktor utama, bukan berarti masyarakat desa berjalan sendiri dalam upaya pengembangan desanya. Di sinilah peran para pemangku kepentingan (stakeholders) pendukung dalam menjalankan perannya masing-masing agar pengembangan desa wisata berhasil. Selain pemerintah desa yang bekerja sama dengan masyarakat desa, peran universitas dari segi akademisi memberi kontribusi khusus dalam pertimbangan metode- 
metode pengembangan desa dan masyarakat, baik melalui pemanfaatan asetnya, yakni dosen dan mahasiswa, maupun jejaring kelembagaan dari universitas tersebut. Kegiatan TriDharma Perguruan Tinggi yang meliputi kewajiban universitas atas Pendidikan, Penelitian, dan Pengabdian kepada Masyarakat menjadi salah satu cara keterlibatan universitas dalam pengembangan desa wisata.

Prodi Pariwisata, Fakultas Ilmu Budaya UGM telah melakukan kegiatan bersama masyarakat Desa Selopamioro mulai 2016 hingga 2018. Keberhasilan pengembangan dengan metode partisipasi masyarakat bukan hal yang mudah dan singkat. Dengan keterlibatan masyarakat, diperlukan komunikasi yang baik dan penyesuaian terhadap kebiasaan dan mata pencaharian masyarakat sehari-hari. Oleh karena itu, kegiatan pengabdian masyarakat yang berkelanjutan dari tahun ke tahun sangat diperlukan. Dari kurun waktu tersebut, terlihat antusiasme masyarakat sangat kuat untuk mengikuti kegiatan-kegiatan, terutama yang berhubungan dengan peningkatan kapasitas untuk pengembangan desanya. Semangat masyarakat inilah yang menjadi modal utama dalam pengembangan desa wisata berbasis partisipasi masyarakat di Desa Selopamioro, baik melalui pokdarwis maupun pemerintah desa dengan keterbukaan dan semangat untuk maju. Kesediaan untuk bekerja bersama dan keterbukaan terhadap potensi serta kendala yang dihadapi menjadikan pendampingan pengembangan desa wisata ini berjalan lancar. Oleh karena itu, pendampingan kepada masyarakat Desa Selopamioro dalam mengembangkan desanya sebagai destinasi wisata pedesaan dirasa penting untuk dilaksanakan.

\section{Metode dan Strategi Pendampingan Pengembangan Pariwisata Pedesaan Desa Selopamioro}

Participatory planning atau perencanaan partisipatif merupakan metode yang paling tepat dalam pengembangan pariwisata di Desa Selopamioro. Terdapat empat strategi yang digunakan dalam kegiatan Pendampingan Pengembangan Pariwisata di Desa Selopamioro. Keempat strategi tersebut, antara lain:

- Strategi Tahapan Berkelanjutan

- Strategi Interaksi langsung dengan masyarakat

- Penggunaan Potensi Jejaring Kelembagaan

- Integrasi Kegiatan Pendidikan bersama Organisasi Mahasiswa.

Dalam strategi pertama, yaitu Tahapan Berkelanjutan, program dan kegiatan setiap tahunnya dirancang sesuai kebutuhan dan dapat dilanjutkan pada tahun berikutnya. Pada setiap akhir dan awal tahun kegiatan pendampingan yang berlangsung selama kurun waktu 2016 hingga 2018 selalu ada kegiatan diskusi bersama masyarakat lokal dan pemerintah setempat. Diskusi ini juga digunakan sebagai kegatan monitoring dan evaluasi guna perencanaan program pada tahun berikutnya. Dalam diagram (Ilustrasi 1) digambarkan tahap kegiatan pendampingan berkelanjutan.

Keunggulan metode pendampingan yang berkelanjutan, selain menghasikan capaian program yang tepat guna dan tepat sasaran, juga meningkatkan peluang interaksi bersama masyarakat. Intensitas interaksi tim Prodi Pariwisata FIB UGM dengan masyarakat berlangsung cukup tinggi. Tim Prodi Pariwisata dalam hal ini memegang tokoh kunci 


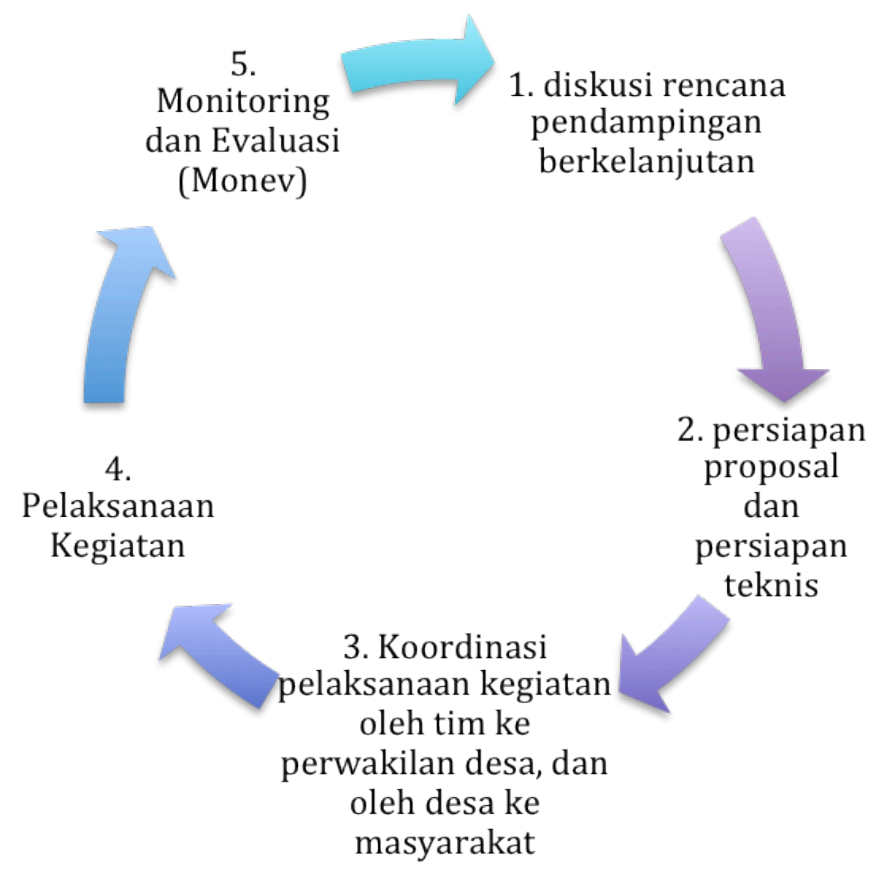

Ilustrasi 1. Diagram Tahap Pendampingan Berkelanjutan di Desa Selomapioro Tahun 2016-2018

yang memiliki pengaruh dan peran yang mampu menggerakkan masyarakat Desa Selopamioro. Tokoh ini terdiri atas tokoh pemerintahan desa dan tokoh organisasi masyarakat.

Dalam pengembangan wilayah pedesaan, hasil dari metode partisipatif akan semakin maksimal dengan dukungan dari jejaring kelembagaan yang mampu mendukung kapasitas masyarakat desa agar semakin mandiri. Universitas berperan sebagai lembaga akademik yang memiliki aset berupa jejaring kelembagaan yang kuat. Keadaan ini sangat disadari oleh tim Prodi Pariwisata bahwa Prodi Pariwisata memiliki aset yang potensial dalam memberi manfaat lebih bagi masyarakat Desa Selopamioro. Dengan kesadaran

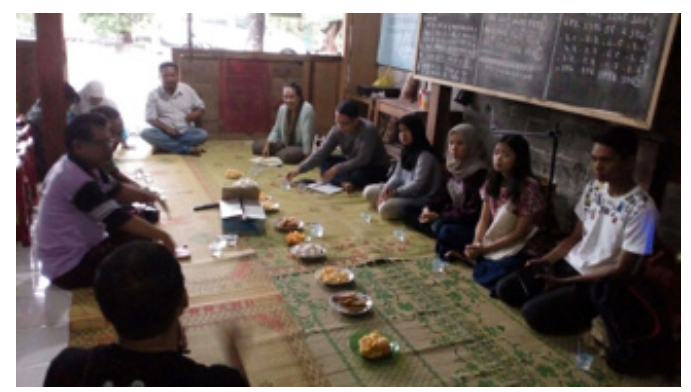

Ilustrasi 2. Diskusi bersama Tokoh Masyarakat Perwakilan Komunitas Seni, Komunitas Pariwisata, Pemuda, dan Organisasi PKK Desa tersebut, tim Prodi Pariwisata memilih tiga komponen jejaring, yaitu (i) Pihak Perhotelan, yang dalam hal ini diwakili oleh Tim dari Jogjakarta Prime Plaza Hotel, (ii) Pihak Desa Wisata Pulesari, dan (iii) Alumni Prodi Pariwisata UGM. Ketiganya berperan sebagai sumber daya dalam mentransfer pengetahuan bagi masyarakat, baik secara langsung maupun tidak langsung.

Kegiatan Pengabdian kepada Masyarakat ini akan membawa kebermanfaatan lebih bagi institusi pengusung kegiatan, yakni Prodi Pariwisata FIB UGM, apabila 


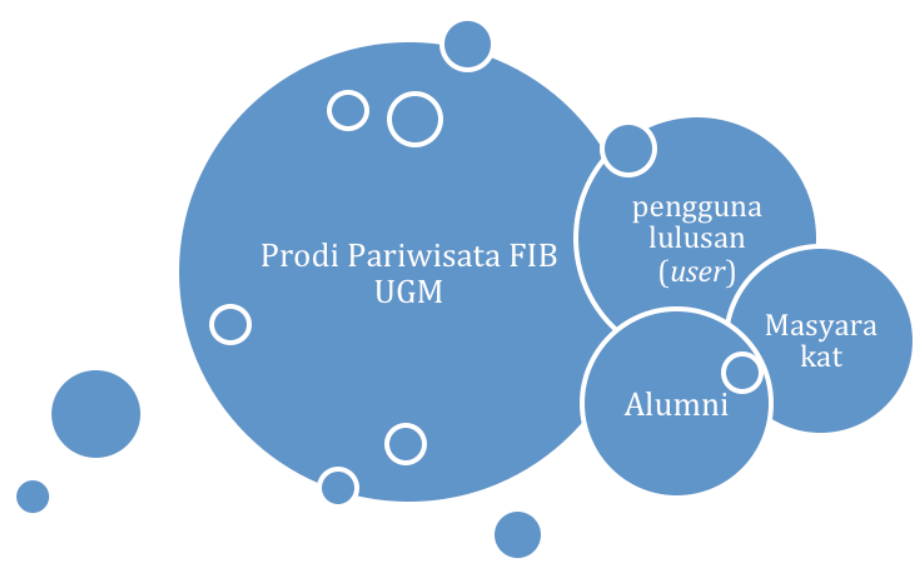

Ilustrasi 3. Peta Jejaring Kelembagaan Prodi Pariwisata

dapat mengintegrasikannya dengan aspek kegiatan TriDharma yang lain. Prodi Pariwisata FIB UGM pada kesempatan ini mengajak mahasiswa untuk turut aktif dalam program pengabdian yang berkelanjutan ini, mulai dari kegiatan diskusi, perencanaan dan persiapan kegiatan, koordinasi dengan tim desa, pelaksanaan kegiatan, hingga monitoring dan evaluasi. Keterlibatan mahasiswa pada setiap tahun kegiatan tidak selalu sama. Mahasiswa bebas memilih keterlibatannya dalam program yang sesuai dengan minat masing-masing, dengan koordinasi melalui Organisasi Mahasiswa, Himpunan Mahasiswa Pariwisata (HIMAPA) FIB UGM. Ada tiga divisi dalam organisasi HIMAPA yang terlibat dalam program ini, yaitu (i) Divisi Pengabdian Masyarakat, (ii) Divisi Penelitian, dan (iii) Divisi Media.

\section{Kegiatan Pendampingan kepada Masyarakat pada Pengembangan Wisata Perdesaan Selopamioro}

\section{Kegiatan 1. Sosialisasi Desa Wisata}

Sosialisasi merupakan tahap awal membangun semangat masyarakat dan kepercayaan terhadap tim pendamping. Semangat dan kepercayaan masyarakat merupakan modal penting untuk menggerakkan kegiatan melalui partisipasi. Oleh karena itu, pada November 2016, Prodi Pariwisata memulai kegiatan pendampingan pengembangan wisata pedesaan di Desa Selopamioro dengan kegiatan Sosialisasi Pengembangan Pariwisata, yang dilaksanakan di Embung Song Bolong oleh tim Pengabdian kepada Masyarakat dan bekerja sama dengan Pemerintah Desa Selopamioro, serta dihadiri oleh perwakilan kelompok sadar wisata (pokdarwis), kelompok penggiat PKK Desa, Karang Taruna, kelompok seni, dan sebagian masyarakat umum.

\section{Kegiatan 2. Pengamatan Potensi Daya Tarik Wisata}

Kegiatan pengamatan potensi atraksi desa wisata dilaksanakan pada Oktober 2016. Kegiatan ini dilaksanakan bersamaan dengan pengamatan homestay wisata. Kegiatan ini berlangsung secara intensif antara dosen-mahasiswa-perwakilan masyarakat, baik diskusi 
secara langsung maupun menggunakan media komunikasi. Hasilnya adalah kesepakatan prioritas pengembangan di titik lokasi wisata yang dianggap paling berpotensi untuk dijadikan sebagai atraksi wisata unggulan. Terdapat tiga lokasi wisata unggulan yang dipilih, namun hingga akhir kegiatan pendampingan pada akhirnya hanya dua lokasi yang dikembangkan maksimal karena salah satu atraksi unggulan rusak terkena bencana banjir dan tanah longsor.

Daya tarik pertama yaitu area jembatan gantung yang menghubungkan antara Desa Selopamioro dan desa di seberang bukit, yaitu Desa Srihardjo. Desa ini merupakan jalur alternatif bagi masyarakat di kedua desa untuk saling menyeberang. Daya tariknya yaitu pemandangan desa yang dapat dilihat dari jembatan ini sangat digemari oleh kalangan pegiat fotografi, terutama saat matahari terbit atau matahari tenggelam. Namun, pada 28 November 2016 terjadi bencana banjir dan tanah longsor di sebagian wilayah Desa Selopamioro dan jembatan ini termasuk salah satu yang rusak akibat bencana tersebut.

Daya tarik kedua yaitu Embung Song Bolong karena lokasinya berada di area yang agak tinggi dan telah terdapat fasilitas gazebo. Pokdarwis bekerja sama dengan kelompok PKK dalam mengembangkan wisata kuliner. Strategi yang digunakan yaitu menjual hasil usaha unggulan desa di lokasi ini. Pengunjung diharapkan memperoleh pengalaman yang baik di embung ini sehingga mereka akan melakukan promosi melalui word to mouth kepada publik. Hingga saat ini, area embung ini digunakan untuk kegiatan festival desa atau acara-acar lainnya.

Daya tarik yang ketiga yaitu Sungai Selopamioro. Masyarakat merancang atraksi susur sungai dengan bantuan kapal karet sebagai hibah dari Kementerian Desa, Pembangunan Daerah Tertinggal dan Transmigrasi Republik Indonesia (Kemendesa) pada 2017. Pada area sekitar titik tambat kapal dibangun gazebo untuk menyediakan fasilitas makanan dan minuman. Atraksi ini dipromosikan melalui media situs web desa dan media sosial lainnya.

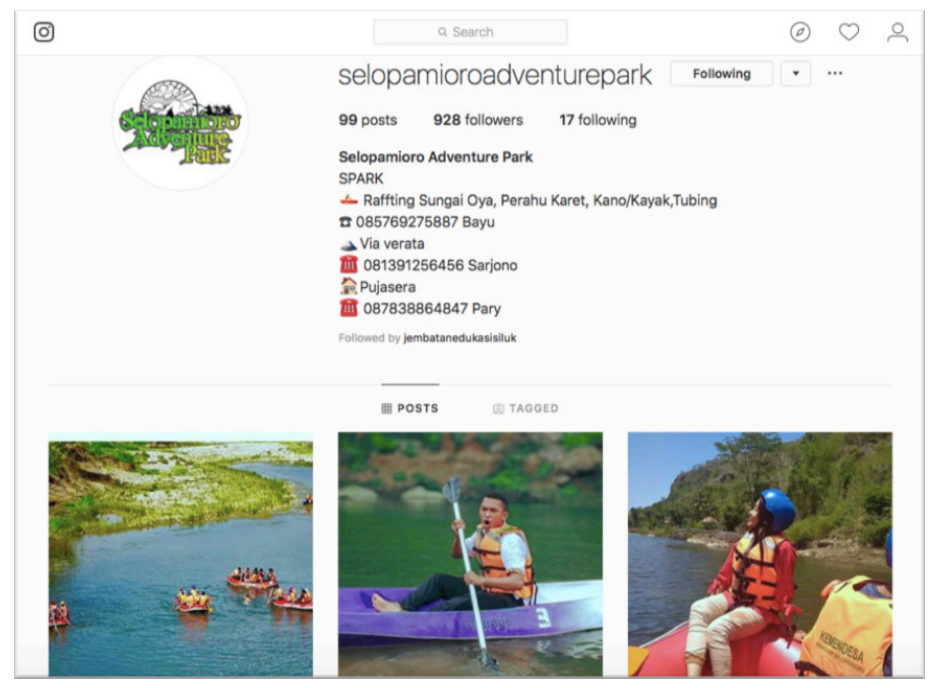

Ilustrasi 4. Media Sosial Instagram Selo Adventure Park (SPARK) 


\section{Kegiatan 3. Pengamatan Homestay Wisata}

Pengamatan akomodasi wisata berlangsung selama dua hari, yaitu pada 21-22 Oktober 2017. Observasi dilaksanakan terhadap beberapa titik daya tarik oleh mahasiswa-dosen Prodi Pariwisata FIB UGM dan perwakilan masyarakat. Kegiatan ini melibatkan 20 mahasiswa Prodi Pariwisata untuk diterjunkan bekerja bersama masyarakat. Mahasiswa dibagi menjadi dua kelompok untuk dapat menjangkau titik daya tarik dan homestay untuk kemudian didiskusikan pada Sabtu, 21 Oktober 2017. Hasil dari kegiatan pengamatan akomodasi dan diskusi masyarakat adalah Dusun Jetis diprioritaskan dalam pengembangan akomodasi homestay sebagai satu dusun percontohan. Renacana berikutnya adalah replikasi manajemen homestay di dusun lain hingga merata di seluruh Dusun yang ada di Desa Selopamioro.

\section{Kegiatan 4. Workshop dan Pelatihan Pengelolaan Homestay}

Workshop dan pelatihan pengelolaan homestay dilaksanakan pada 26 November 2017 sebagai rangkaian dari kegiatan pengamatan akomodasi wisata. Ide pelaksanaan kegiatan ini berasal dari tokoh pokdarwis yang turut serta dalam pengamatan akomodasi wisata bersama HIMAPA pada bulan Oktober. Pengetahuan awal mengenai homestay dirasa perlu sebagai bekal perintisan homestay. Penggunaan strategi jejaring kerja sama dengan desa wisata lain bermanfaat untuk memberikan contoh pengelolaan wisata di desa wisata yang telah lebih dahulu berdiri, dalam hal ini dipilih Desa Wisata Pulesari untuk membagikan pengalamannya. Workshop ini dirasa berhasil membangkitkan semangat masyarakat, meskipun tidak semua peserta berasal dari Dusun Jetis. Mereka merasa apabila Dusun Jetis kelak sukses dengan homestay, ilmu yang diperoleh dapat ditularkan ke dusun-dusun lain.

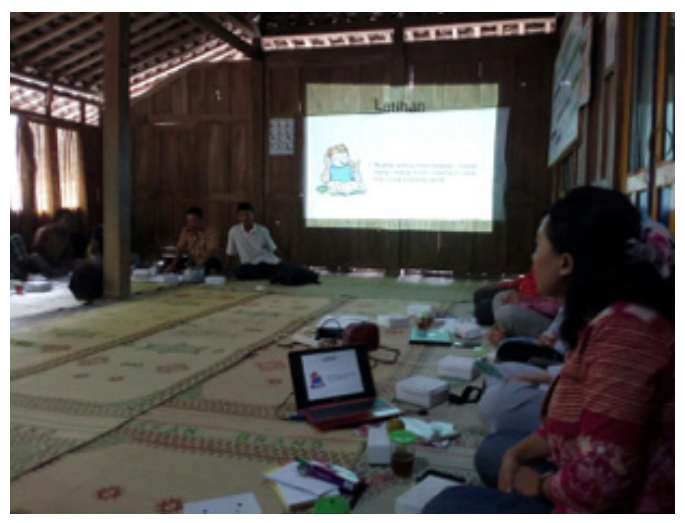

Ilustrasi 5. Paparan Materi Pengelolaan Homestay dari Narasumber Desa Pulesari (Bapak Didik Irwanto)

\section{Kegiatan 5. Workshop Tata Graha}

Dilaksanakan pada 15 Juli 2018, workshop ini juga merupakan rangkaian kegiatan setelah workshop pengelolaan homestay, dengan peserta terdiri atas masyarakat Desa Selopamioro yang terlibat dalam kegiatan usaha akomodasi pariwisata (homestay) dan bidang yang berhubungan dengan hospitalitas. Selain itu, workshop dilaksanakan di rumah salah satu warga yang terletak di Dusun Jetis, Desa Selopamioro. Tempat pelaksanaan workshop sangat mendukung keberhasilan acara karena pengaturan ruangnya dapat mendukung interaksi antara peserta workshop dan narasumber dengan nyaman. Interaksi terjadi pada saat sesi diskusi dan praktik Tata Grha. Strategi jejaring kerja sama juga dimunculkan dalam pelaksanaan workshop ini, yaitu dalam pemilihan narasumber dari praktisi perhotelan yang berasal dari Prime Plaza Hotel Yogyakarta, antara lain, Bapak Imam Hidayat dari Divisi Housekeeping dan Bapak Leonardo Teguh dari Divisi Food and Beverage. 


\section{Penutup}

Kegiatan Pengabdaian kepada Masyarakat di Desa Selopamioro yang bersifat berkelanjutan dan dilaksanakan dalam rentang waktu multitahun ini memberikan dampak positif terhadap pengembangan kegiatan pariwisata. Dengan metode berkelanjutan, secara langsung terjadi monitoring dan evaluasi terhadap kegiatan yang telah dilaksanakan. Metode berkelanjutan dan partisipasi juga memberi ruang kepada masyarakat untuk terlibat langsung sehingga mereka timbul rasa memiliki terhadap daerahnya. Hal inilah yang akan menjadi kunci keberhasilan kegiatan pariwisata sekaligus juga menjadi barrier terhadap dampak negatif pariwisata.

Sebagai institusi akademik, jejaring kelembagaan merupakan kekuatan yang dapat dimanfaatkan untuk pengembangan masyarakat, baik pihak internal, yakni mahasiswa, maupun eksternal, yakni alumni dan institusi swasta. Dengan adanya kerja sama ini, kegiatan pengembangan desa wisata dapat berhasil dengan baik. 